\title{
A SaaS-Based Logistics Informatization Model for Specialized Farmers Cooperatives in China
}

\author{
Zhongqiang Liu, Kaiyi Wang ${ }^{*}$, Shufeng Wang, Feng Yang, and Xiandi Zhang \\ Beijing Research Center for Information Technology in Agricultural, Shuguang \\ Huayuan Middle Road 11\#, 100097 Beijing, China \\ \{liuzq, wangky, wangsf, yangf, zhangxd\} @nercita.org.cn
}

\begin{abstract}
The logistics informatization of Specialized Farmers Cooperatives (SFC) plays an important role in the development of agriculture, and Softwareas-a-Service (SaaS) is the development trend of information technology (IT). Firstly, the state-of-the-art of IT on SFC and the enlightenment SaaS to the IT application in logistic are introduced. Then, analyzing of the characteristics of logistics management system for SFC based on SaaS, we explore a SaaS-based logistics informatization model for SFC in China, and some key technologies to model application are also discussed, such as software architecture, system security and data modeling. Finally, some suggestions are put forward for a large-scale promotion of the model.
\end{abstract}

Keywords: Informatization, SaaS, Model, Specialized Farmers Cooperatives, Logistics.

\section{Introduction}

Along with the continuous development of SFC and agriculture, as the intermediary organizations that connect the markets and farmers, cooperatives play an increasingly significance affect in agricultural logistics [1]. The application of information technology has improved the logistics management level of SFC .It also has brought about the healthy development of the cooperatives. However, information talent shortage, information infrastructure imperfect and high information costs become the bottleneck of information technology for SFC at this stage.

SaaS is a new kind service mode of Software that provides a new strength for informatization construction for SFC [2]. The products based on SaaS have some prominent advantages and characteristic, such as good expansibility, easy extensibility, strong flexibility and low using threshold [3]. To solve the existing problems in the process of IT construction, we will explore the service model of logistic information suitable for SFC based on SaaS. The feasibility and implementation plan of realizing agricultural logistics information on SaaS mode is studied in this paper according to the agricultural logistics management system for SFC.

\footnotetext{
* Corresponding author.
} 


\section{Status of Logistics Informatization for SFC}

As the main implementing subject of agricultural information, SFC is also the most important link in the agricultural informatization chain [4]. By the end of 2009, there are 246.4 thousand farmers' cooperatives with 21 million households (accounting for $8.2 \%$ of total households) registered in the industrial and commercial management department accordance with law. The services expand gradually from the production area to the circulation and processing integration business. Information technology builds an important platform for improving the logistics management level, the service level and the marketing ability of SFC to meet the unceasingly scale expansion and functional improvement and service quality improvement of SFC. The IT in logistics can provide real-time logistics information for SFC. It can help cooperatives make a scientific decision to reduce blindness in logistics and improve the efficiency and economic benefit, etc. Anyhow, the construction of IT for logistic can accelerate the development of SFC.

Agricultural products logistics information is an important content of the SFC of informational management. It can promote the farmers' cooperatives, as well as can be good for the mode of informatization and scientific management of cooperatives [4]. Introducing a modern management mode of enterprise logistics to SFC can make the logistics management of cooperatives more standard and scientific. Agricultural products logistics management system for SFC can not only apply the information technology into cooperatives but also be extended to the information from production to marketing to realize information management.

Currently, the study on the IT for SFC logistics has carried out with a lot of achievements. However, in the process of IT construction there are a lot of questions as follows. Firstly, we are lack of information knowledge and talent even we have a stronger information consciousness. Secondly, information infrastructure is equipped perfectly, but access to information and information interaction are imperfectly. Thirdly, lack of funds became an obstacle to improve the level of logistics information. Lastly, stronger logistics information service demand but backward information service means, etc. The reasons are the underlying causes that restrict the IT construction for logistics has not been thought about deeply and the service model for logistic information hasn't been explored. So, we have not gain the maximum efficiency of IT and the service model for logistic information hasn't been explored.

\section{The Enlightenment SaaS to Logistic Informatization of SFC}

\subsection{SaaS}

SaaS is a unique and innovative hosting type application service. It also is a software application mode as the development of the internet technology and software. The main features of SaaS service mode is SaaS service providers purchase IT infrastructure and deploy IT environment, and enterprise purchase software services. Service providers deploy the software in his uniform. Then, customers can order the software services via the Internet according to their actual needs and get the service from the Internet, and pay fees via the Internet according to the service they ordered. 
Service providers can ensure every enterprise data security and confidentiality through effective technical measures [5].

\subsection{The Superiority of SaaS Applied in Logistics Informatization of SFC}

Compared with the traditional software, SaaS has four prominent advantages such as low construction cost, low maintenance, low threshold and low investment risk applications. That is why it can cover a logistics information market. SaaS service mode applied in the construction of IT for logistics of SFC has the following advantages.

\subsubsection{Low Level Demands}

The demand of SFC to logistics informatization is low level, which accords with the concept of SaaS, as configurable, customizable and extensible concept [6]. Logistics informatization of SFC is mainly to the underlying basis of information. That needs the information products can immediate access to data, respond quickly to market, improve decision making and seize the opportunities before us. Because of the small business coverage, SFC doesn't need the large and comprehensive information products. SaaS makes SFC purchase and expand its modules online, and enjoys information good results with muti-function and low cost to minimize the "chicken ribs" effect that traditional software produces [7].

\subsubsection{Regional and Diversification Needs}

Logistics of SFC serves farmers and members. It needs automation and active service in order to ascend cooperatives' logistics service ability and reduce cost [8]. This is a primary problems that the construction of IT for logistic of SFC to solve. But the traditional software system cannot adapt to rapid market changes and maintain advancement of the present situation of information technology. This is determined by the traditional software model. The system framework of SaaS follows the configurable, extensible, customizable features of open architecture. According to the market and the demand on logistics services, cooperatives may order the corresponding software services to reconfigure system from the service provider to serve market and farmers better. It also can customize individualized function according to the logistics business to support a rapid development of logistics business.

\subsubsection{Comprehensive Services}

SaaS mode will make it possible that different stages of the supply chain and different types of SFC provide services collaboratively. Currently, the SFC has a smaller coverage, mostly just involving a small portion of content in agricultural industrialization chain. As a single type of service providers, cooperative itself is unable to finish all the service requirements throughout the supply chain. Many services require other cooperatives for collaborative operation. While traditional software system flow is hard to breakthrough the border among cooperatives. There would be a lot of the repeated work because of the information in a large share on the supply chain link. The logistics efficiency and service capacity of cooperative cannot have a fundamental improvement. Therefore, SaaS has a good applicability to the cooperative with logistics service function. 
Presently logistics business of SFC mainly embodies the characteristics of low concentration in the cooperation, the low degree of logistics information and the low output of IT construction for a shortage of funds and so on. But all of these are very conducive to the development of the SaaS in cooperatives. SaaS mode makes cooperatives in logistics information process can enjoy lower investment returns, and reduce the high difficulty in the logistics information to help cooperatives build an information era in a short time. It will bring into a greater profit, and play the logistics service function fully.

\section{SaaS-Based Logistics Informatization Model for SFC}

Analyzing of the characteristics of logistics management system for SFC on SaaS, we explore a SaaS-based logistics informatization model for SFC. The model full considers the features of logistics management system, such as individuation, integration, differentiation, etc. The key technologies for model application, as software architecture, system security and data modeling have also been explored. The structure of the model is shown in figure 1 .

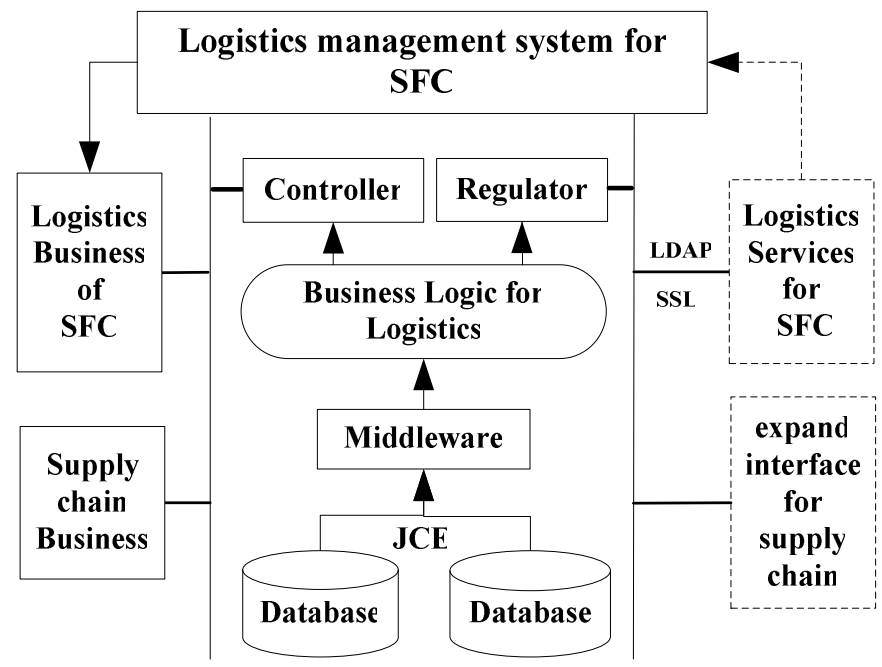

Fig. 1. SaaS-based logistics informatization model for SFC

\subsection{Model Analysis}

The emergence of SaaS to SFC opened a road leading to the information. But there are some difference between the characteristics of information product in SaaS mode and traditional mode. The model firstly extracts logistics business process, and then screens and integrates services through the controller and regulator, finally generates logistics information product. The model takes agricultural logistics business of SFC as a prototype with the following features. 


\subsubsection{Various Complexity and Individualized Multi-user Interface}

The main business of farmers' cooperatives involves agriculture, forestry, animal husbandry and fishery, covering many fields of farm products production, storage, processing, marketing, etc. Different types of agricultural logistics management system have more than one difference in logistics links, logistics subject, logistics packaging and logistics information mark, etc. Fully considering logistics demand in different main business model of cooperatives, the model provides a multi-user interface to cooperatives with personalized and free. Cooperatives can distribute characteristics of agricultural logistics management and logistics information subject, according to different kinds of agricultural logistics. For some cooperatives with more complex business in agricultural varieties, the model offers a variety of different complexity system interface. The agricultural logistics management system based on the model can satisfy the concern and emphasis of different types of cooperative.

\subsubsection{Expanding Business Logic}

With the cooperation of a chain logistics link to the full extension, narrow supply is becoming to general logistics. So, the whole process and scientific management of agricultural products supply chain will become the most important content of the operation mode and cooperative information. The model should first meet the need of the application of IT for logistics, and then, should have the business expansion logic function, allowing the system based on the model can be extended to the information along industrial production management and marketing.

On the basis of the supply chain, production and sales of agricultural products, the model hold on the basic information of the system from the production links to the sales link. The integrated logistics supply construction management system based on the model to realize the full information management, supply and the industrialized operation of agriculture, production, circulation, processing and sales link organically, effectively solve the cooperatives in industry production and marketing problem.

The range of logistics management system on SaaS can be extended to the production before, during and after the process, and have online transactions and realtime management etc. The system also can monitor each loop from manufacturing to market sales, and will largely enhance the ability of driving and marketing.

\subsubsection{Flexible Data Structure}

The most challenge that different cooperatives use the same software system installation examples in SaaS is how to create multi-user data model, and to support the different data structure. Cooperatives order their logistics management software according to their management way and the system execute the business absolutely with a bigger difference way. Different business process requires different data structure. For the characteristics of Cooperatives for dispersive location, main business involving multiple fields, no unified standard features and so on, the model achieve several sets of data structures support through the corresponding relationship of real data structure and logical data structure. A logistics management system which constructed for farmers' cooperatives based on this model is very flexible software. 


\subsection{Model Application}

Considering the main and expansion of business that the model application may involve, the applied mode and realization technology of the model are discussed. The structure of the model application is shown in figure 2. The point a logistics management system in SaaS to apply successful is the system architecture, service oriented architecture and data safety. One isolate design according to the key problems is given below by the model.

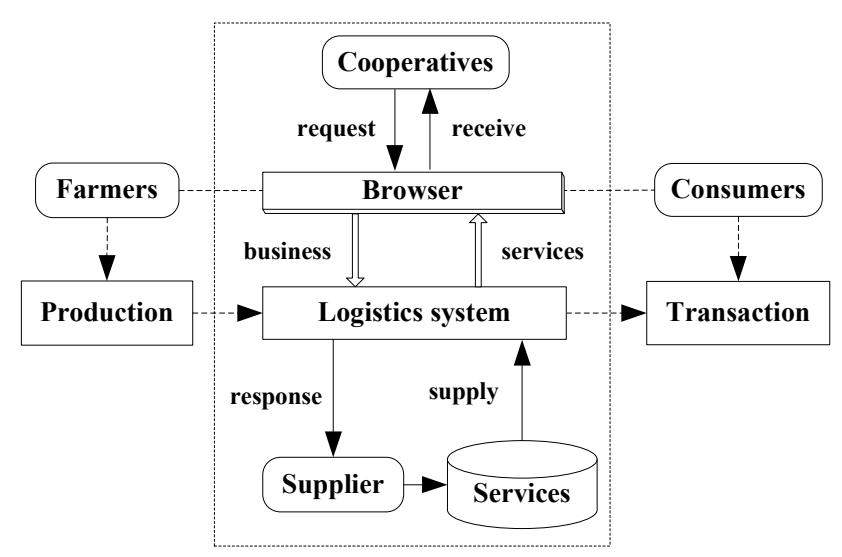

Fig. 2. The structure of the model application

\subsubsection{Service Oriented to Build Software}

The system architecture of SaaS is based on service-oriented architecture. The business process is decomposed into service components. And then it builds various service modules by the specific implementation technology [9]. First, the design of business-driven can more quickly meet logistics management requirements of different main business of cooperatives. Second, it can improve system reusability according to the logistics demand for change quickly and low price update service. Third, it can integrate the service of the logistics management system for SFC and other services in the supply chain, and finally realize the integration of brands.

\subsubsection{Multilevel Security Architecture Design}

The responsibility shift of data management on SaaS mode makes safety priority higher in the software architecture. In data security, secure socket models use secure socket layer (SSL) [10] to protect data transmission in order to ensure the safety, reliability and safety, under the premise of minimizing the safety factor of influence on system performance. On safety design of authentication and authorization, in order to improve the system integration and user authentication efficiency, the model uses lightweight directory access protocol (LDAP) to unified manage user authentication information. On data security, the model makes use of Java cryptographic key data extensions (JCE) to implement encryption and decryption. 


\subsubsection{Adaptive Data Isolation Strategy}

Procedures and databases are requested by SaaS mode to build in multi-user models and make independent between cooperatives [11]. Middleware provides a new concept for SaaS mode [12]. It can effectively shield in different database system access method and the user interface, also provide users with a public interface of distributed database access of heterogeneous platform. The model design which based on middleware according to the characteristics of a business, can make the logistics business of SFC logic layer to handle database data with unified way, and make the data more flexible. Cooperatives that have a low safety requirements and a small amount of data will use a shared database. And the exclusive one will be used for safety requirements.

\section{Conclusion and Suggestion}

The informatization for SFC is of great significance for the rapid development of cooperatives and the promoting of IT in agriculture. The paper analyzes the characteristic of agricultural logistics management system for SFC and explores the construction of IT technical scheme for SFC. But because of the later of starting, narrow range of logistics business scope, low level of IT for SFC, and the application status of SaaS in agricultural logistics field, the model of large-scale applications needs to consider long-term strategic objectives. It should be used in a certain types of cooperatives, such as greenstuffs. Along with the continuous development of logistics business of SFC and the gradually complete of SaaS mode, the logistics information products for SFC based on SaaS will have broad development prospects.

Acknowledgments. This work is supported by National 11th Five-year Plan for Science \& Technology of China under Grant no. 2009BADB6B02.

\section{References}

1. Qian, J., Yang, X., Liu, X.: Management Patterns of Farmer Professional Associations Based on Information Technologies. Journal of Agricultural Mechanization Research 30(6), 6-9 (2008)

2. Choudhary, V.: Comparison of Software Quality under Perpetual Licensing and Software as a Service. Journal of Management Information Systems 24(2), 141-165 (2007)

3. David, D.: Software as a Service. Dr.Dobb's Journal 31, 10 (2006)

4. Liu, Z., Wang, K., Yu, G.: Informationization Solution for Farmers' Cooperatives. Journal of Agricultural Mechanization Research 32(1), 1-4 (2010)

5. Campbell-Kelly, M., Garcia-Swartz, D.D.: From Products to Services: the Software Industry in the Internet Era. Business History Review 81, 735-764 (2007)

6. Wu, H.: Analysis and Design of Dining Management System Based on SaaS. Dalian University of Technology, Dalian (2008)

7. Ma, D., Seidmann, A.: The Pricing Strategy Analysis for the Software-as-a-service Business Model. In: Altmann, J., Neumann, D., Fahringer, T. (eds.) GECON 2008. LNCS, vol. 5206, pp. 103-112. Springer, Heidelberg (2008) 
8. Li, D.: China's Rural Information Development Report. Publishing House of Electronics Industry, Beijing (2009)

9. Laplante, P.A., Zhang, J., Voas, J.: What's in a name? Distinguishing between SaaS and SOA. IT Professional 10(3), 46-50 (2008)

10. Zhu, S.: Online Application of Circulation on SaaS Mode. China Computer \& Communication 3, 63-64 (2010)

11. Ma, D.: The Business Model of Software as a Service. In: The 2007 IEEE International Conference on Services Computing (2007)

12. $\mathrm{Hu}, \mathrm{F} .:$ Analysis and Discussion of Logistics Information Platform Based on SaaS mode. Knowledge Economy 10, 106 (2009) 